\title{
Can sunlight affect COVID-19 outcomes? What is the available evidence?
}

\author{
Mohammad Reza Khazdair' ${ }^{1}$ Andy Goren ${ }^{2}$ \\ ${ }^{1}$ Cardiovascular Diseases Research Center, Birjand University of Medical Sciences, Birjand, Iran \\ ${ }^{2}$ Applied Biology Inc., Irvine, CA, USA
}

\section{Dear Editor,}

Coronavirus disease 2019 (COVID-19) has rapidly spread into a global pandemic that challenges the economic, medical, and public health stability of nations worldwide. 'Severe acute respiratory syndrome coronavirus (SARS-CoV)-2, first identified in China in December 2019 as the "novel coronavirus," causes COVID-19 by utilizing angiotensin-converting enzyme 2 receptors and transmembrane protease, serine 2 (TMPRSS2, located on host cell surfaces) for entry and infection. Thus, TMPRSS2 is required for SARS-CoV-2 infectivity. ${ }^{1}$

Interestingly, total prostate-specific antigen levels vary by season. The prolonged daylight hours of spring and summer are associated with reduced androgen sensitivity, which lowers TMPRSS2 expression and subsequently reduces SARS-CoV-2 infectivity. Conversely, the shortened daylight hours of autumn and winter are associated with increased SARS-CoV-2 infectivity. ${ }^{2}$

Dopico et al. ${ }^{3}$ demonstrated that the cellular composition of blood also varies by season: soluble interleukin (IL)-6 receptor and C-reactive protein concentrations increase during winter and estradiol receptor gene expression increases during summer. This is pertinent because SARS-CoV-2 infections cause cytokine storms and systemic inflammatory responses that are mediated by the release of large amounts of pro-inflammatory cytokines and chemokines (e.g., IL-1b, IL-6, and interferon- $\alpha$ ) from immune effector cells. ${ }^{1}$

Sunlight exposure mediates the conversion of previtamin D3 (precholecalciferol) into vitamin D3 (cholecalciferol) by liver enzymes. Vitamin D receptors are highly expressed by monocytes and by B and T lymphocytes, which modulate immune cell function. Thus, vitamin D deficiency is primarily associated with increased susceptibility to, and severity of, many infectious diseases. More specifically, it is associated with low concentrations of the pro-inflammatory cytokine IL6, which plays a significant role in COVID-19-induced acute respiratory distress syndrome. In addition, low 25 -hydroxyvitamin D concentrations may increase COVID-19 mortality. ${ }^{4}$ Taken together, studies indicate that sunlight improves immunity by increasing vitamin D production and thus may be useful for the treatment of COVID-19.

The environmental survival of viruses such as SARS-CoV-1 depends on factors, including sunlight, humidity, and temperature. On the other hand, 90\% of SARS-CoV-2 is inactivated every 6.8 minutes in simulated saliva and every 14.3 minutes in culture media exposed to simulated sunlight (representative of summer at $40^{\circ} \mathrm{N}$ latitude). Indeed, during summer, 11 to 34 minutes of midday sunlight can inactivate $\geq 90 \%$ of SARS-CoV 2 viruses in most locations. ${ }^{5}$

In conclusion, sunlight modulates immune system function by inducing vitamin $D$ production.
elSSN: 2383-4625

Received: 15 March 2021

Revised: 13 April 2021

Accepted: 20 April 2021

Correspondence to:

Mohammad Reza Khazdair

Cardiovascular Diseases Research

Center, Birjand University of Medical

Sciences, Ghafari Street, Birjand, South

Khorasan 9717853111, Iran

E-mail:khazdairMR@Bums.ac.ir

ORCID

https://orcid.org/0000-0001-9854-6121

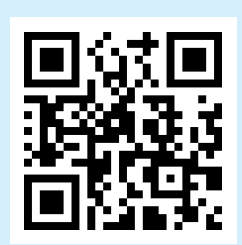

How to cite this article:

Khazdair MR, Goren A. Can sunlight affect COVID-19 outcomes? What is the available evidence?. Clin Exp Emerg Med 2021;8(3):249-250. https://doi. org/10.15441/ceem.21.045

This is an Open Access article distributed under the terms of the Creative Commons Attribution Non-Commercial License (https:// creativecommons.org/licenses/by-nc/4.0/). 
It also reduces androgen sensitivity and lowers TMPRSS2 expression. Considering that SARS-CoV-2 are dependent on TMPRSS2 for infectivity, sunlight may be useful in the fight against SARSCoV-2.

\section{CONFLICT OF INTEREST}

No potential conflict of interest relevant to this article was reported.

\section{REFERENCES}

1. Guan WJ, Ni ZY, Hu Y, et al. Clinical characteristics of corona- virus disease 2019 in China. N Engl J Med 2020;382:1708-20.

2. Salama G, Noirot 0 , Bataille $V$, et al. Seasonality of serum prostate-specific antigen levels: a population-based study. Eur Urol 2007;52:708-14.

3. Dopico XC, Evangelou M, Ferreira RC, et al. Widespread seasonal gene expression reveals annual differences in human immunity and physiology. Nat Commun 2015;6:7000.

4. Laird E, Rhodes J, Kenny RA. Vitamin D and inflammation: potential implications for severity of Covid-19. Ir Med J 2020; 113:81.

5. Sagripanti JL, Lytle CD. Estimated inactivation of coronaviruses by solar radiation with special reference to COVID-19. Photochem Photobiol 2020;96:731-7. 